for this analysis. As in the original analysis, no single complete haplotype within the LD block was sufficiently common to allow demonstration of disease association on the global level. However, using the sliding window approach, associated haplotypes were identified composed of combinations of SNPs 2-8. The individual haplotypes which are overtransmitted within each window together form a larger haplotype composed of the alleles 2211122.

While subtle differences have been found in this reanalysis, this was not found to alter the conclusions drawn previously.

\title{
Unexpected genetic heterogeneity in a large consanguineous Brazilian pedigree presenting deafness
}

Karina Lezirovitz, Eliete Pardono, Maria TB de Mello Auricchio, Fernando L de Carvalho e Silva, Juliana J Lopes, Ronaldo S Abreu-Silva, Jihane Romanos, Ana C Batissoco and Regina C Mingroni-Netto

European Journal of Human Genetics (2008) 16, 660; doi:10.1038/ejhg.2008.2

Correction to: European Journal of Human Genetics (2008) 16, 89-96; doi:10.1038/sj.ejhg.5201917; published online 12 September 2007
Since the publication of the above paper, the authors have identified three typographical errors regarding Table 1 . The amended table is shown below.

Table 1 Summary description of the genotypic data

\begin{tabular}{|c|c|c|}
\hline Genotypic data & $\begin{array}{l}\text { Number of } \\
\text { individuals }\end{array}$ & Pedigree position \\
\hline MY015A mutations in both alleles & 20 & \\
\hline c.10573delA homozygotes & 15 & $\begin{array}{l}\text { V:8, V:12, V:18, V:22, V:23, V:24, V:25, V:27,V:34, Vl:2, } \\
\text { Vl:3, Vl:4, Vl:8, Vl:9 and VI:11 }\end{array}$ \\
\hline $\begin{array}{l}\text { c.10573delA/c.9957_9960delTGAC compound } \\
\text { heterozygotes }\end{array}$ & 5 & $\mathrm{~V}: 1, \mathrm{~V}: 2, \mathrm{~V}: 3, \mathrm{~V}: 4$ and $\mathrm{VII}: 2$ \\
\hline Unsolved cases & 6 & \\
\hline One $M Y 015 A$ mutation detected & 1 & V:17 \\
\hline No MYO15A mutations & 5 & VI:17, VI:19, VII:4, VII:3 and VIII:1 \\
\hline
\end{tabular}

